\title{
Heat Loss Analysis of Outdoor Piping
}

\author{
Miroslav Př́hoda ${ }^{1, *}$, Mária Čarnogurská ${ }^{2}$, René Pyszko ${ }^{1}$, Emil Hlisnikowski ${ }^{1}$, and Jiři Burda ${ }^{1}$ \\ ${ }^{1}$ VSB - TU of Ostrava, Faculty of Materials Science and Technology, Department of Thermal \\ Engineering, 17. listopadu 15, Ostrava - Poruba, 708 00, Czech Republic \\ ${ }^{2} \mathrm{TU}$ of Košice, Faculty of Mechanical Engineering, Department of Power Engineering, \\ Vysokoškolská 4, 04200 Košice, Slovak Republic
}

\begin{abstract}
Although the heat losses of the outdoor piping are minimised by thermal insulation, the distribution of heat from the heating plant to individual consumers of the technological heating media is always accompanied by losses. In the case of large transported volumes of the flowing media, the loss values are negligible. The mathematical and physical analysis of the heat loss of the outdoor heat distribution systems, insulated and non-insulated, has been carried out while using the parameters measured on the real piping system.
\end{abstract}

\section{Introduction}

The heat loss of an outdoor piping is usually calculated while applying the elementary laws for the heat transport [1-6]. However, different piping systems have specific properties, in particular operating temperatures, characteristics of the external environment and insulation materials properties.

The heat loss is a part of the thermal energy of the medium flowing in the pipe into the surrounding environment. The heat loss cannot be completely eliminated, but it may be minimised through the economically bearable measures based on the performed calculations and analyses.

\section{Analytical procedure of expressing the heat loss of the piping}

The heat flow transferred from the insulated surface of the tubular piping, relative to the unit of length, is defined by the linear heat flux $q_{l}$ [1]. The respective formula is as follows:

$$
q_{l}=\frac{P}{l}=\frac{\pi \cdot\left(t_{\mathrm{m}}-t_{\mathrm{a}}\right)}{\frac{1}{2 r_{1} \cdot \alpha_{1}}+\sum_{i=1}^{n} \frac{1}{2 \lambda_{i}} \cdot \ln \frac{r_{i+1}}{r_{i}}+\frac{1}{2 r_{n+1} \cdot \alpha_{2}}} \quad\left(\mathrm{~W} \cdot \mathrm{m}^{-1}\right)
$$

where $P$ is heat flow $(\mathrm{W}), l$ is the piping length $(\mathrm{m}), t_{\mathrm{m}}$ is the temperature of the transported medium $\left({ }^{\circ} \mathrm{C}\right), t_{\mathrm{a}}$ is the temperature of the surrounding air $\left({ }^{\circ} \mathrm{C}\right), \lambda_{i}$ is the thermal conductivity coefficient of the $i^{\text {th }}$ layer of the pipe material $\left(\mathrm{W} \cdot \mathrm{m}^{-1} \cdot \mathrm{K}^{-1}\right), r$ is the radius $(\mathrm{m}), \alpha_{1}$ is the heat transfer coefficient from the transported medium to the internal surface of the piping

\footnotetext{
${ }^{*}$ Corresponding author: miroslav.prihoda@,vsb.cz
} 
$\left(\mathrm{W} \cdot \mathrm{m}^{-2} \cdot \mathrm{K}^{-1}\right), \alpha_{2}$ is the heat transfer coefficient from the external surface to the surrounding air $\left(\mathrm{W} \cdot \mathrm{m}^{-2} \cdot \mathrm{K}^{-1}\right)$.

Heat transfer coefficients $\alpha$ include heat transfer by convection and radiation. The flow inside the piping exhibits a high degree of turbulence and therefore it can be assumed that the temperature of the inner wall of the piping $t_{1}$ is practically equal to the temperature of the transported medium, $t_{1} \approx t_{\mathrm{m}}$. Therefore, the equation (1) can be simplified as follows:

$$
q_{l}=\frac{\pi \cdot\left(t_{1}-t_{\mathrm{a}}\right)}{\sum_{i=1}^{n} \frac{1}{2 \lambda_{i}} \cdot \ln \frac{r_{i+1}}{r_{i}}+\frac{1}{2 r_{n+1} \cdot \alpha_{2}}} \quad\left(\mathrm{~W} \cdot \mathrm{m}^{-1}\right)
$$

The key problem in solving the equation (2) is to identify the coefficient $\alpha_{2}$ which includes the convection and radiation from the outer surface. As for the convection, it is the natural convection characterised not only by the Nusselt criterion $(\mathrm{Nu})$, but also by the product of the Grashof number $(G r)$ and the Prandtl number $(P r)$, i.e., by the Rayleigh criterion $(R a)$, as follows:

$$
N u=f(G r \cdot P r)=f(R a)
$$

According to [2], the heat transfer by natural convection from the cylindrical surface to the surrounding environment can be described by the following equation:

$$
N u=\left\{0.752+0.38 \cdot\left[R a \cdot f_{3}(\operatorname{Pr})\right]^{1 / 6}\right\}^{2}
$$

In the similarity criteria in equations (3) a (4), for the horizontal piping the characteristic parameter $b$ is replaced with the following value:

$$
b=\frac{\pi}{2} \cdot d \quad(\mathrm{~m})
$$

where $d$ is the external diameter of the piping $(\mathrm{m})$.

The following equation applies for function $f_{3}(P r)$ :

$$
f_{3}(P r)=\left[1+\left(\frac{0.559}{P r}\right)^{9 / 16}\right]^{-16 / 9}
$$

The most complicated task within the solution of the radiative heat transfer between different objects is the identification of the view factor $\varphi$. Outdoor piping systems consist almost exclusively of round pipes. For example, for two parallel cylindrical surfaces shown in Figure 1, the following equation applies to the mean view factor [7]:

$$
\varphi_{12}=\frac{1}{2 \pi} \cdot\left[\pi+\sqrt{K^{2}-L^{2}}-\sqrt{K^{2}-M^{2}}+M \cdot \arccos \frac{M}{K}-L \cdot \arccos \frac{L}{K}\right]
$$

The $K, L$ and $M$ coefficients are determined as follows:

$$
K=\frac{r_{2}}{r_{1}}+\frac{s}{r_{1}}+1, \quad L=\frac{r_{2}}{r_{1}}+1, \quad M=\frac{r_{2}}{r_{1}}-1
$$




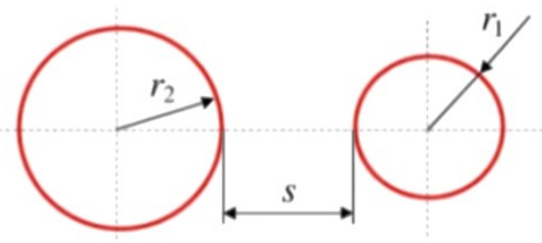

Fig. 1. Two parallel pipes.

For systems consisting of multiple parallel pipes, the Hottel's crossed-string method can be used to determine the view factors [8].

\section{Heat loss of the selected distribution piping}

The measurements were carried out on the piping system transporting the blast-furnace gas, blast-furnace wind, steam and water (Figure 2). The pipes in the upper row, designated with numbers 1 and 3, contained the blast-furnace wind and the pipe no. 2 contained the blastfurnace gas (BFG). The lower row of pipes contained the medium-pressure steam (no. 4), secondary hot water (no. 5) and primary hot water (no. 6). The whole piping system was located above the roof (no. 7). All pipes, except for the one with the blast-furnace gas, were insulated. The photograph of the pipes and the image taken by thermal imager are shown in Figure 3.

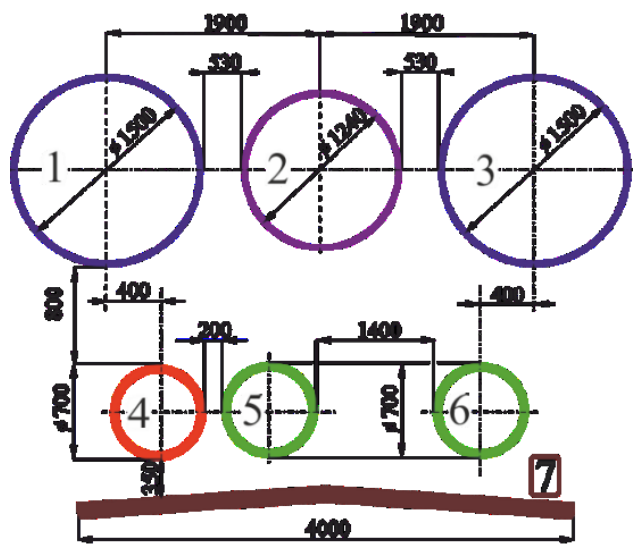

Fig. 2. Geometry of the piping system.

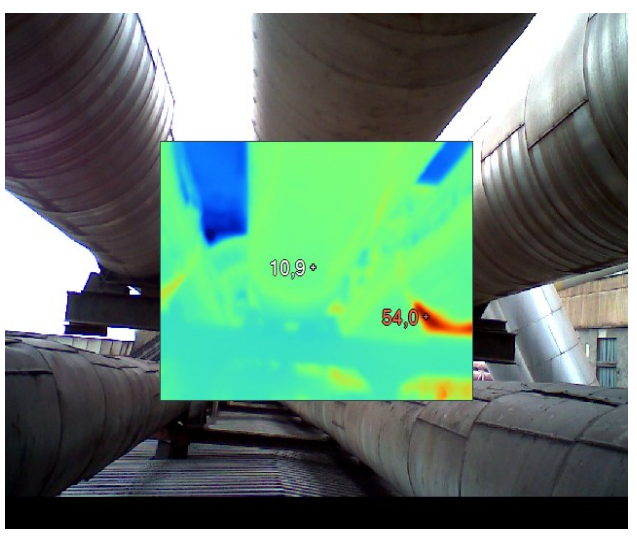

Fig. 3. The photograph and the thermal image of the piping system.

\subsection{Experimental measurements}

The parameters necessary for the heat loss calculation were identified by experimental measurements. The experiment was carried out using the following measuring devices: contact thermometer Omega HH-11 with thermocouple type K, thermal camera Fluke VT 04, weather station GIOM 3000 and data logger Voltcraft DL-111K.

The results of ambient temperature measurement are shown in Figure 4.

Table 1 contains experimentally identified temperature and emissivity values at three different ambient temperatures. The emissivity of the insulating surface (in the case of BFG piping) was identified by a thermocamera after it was calibrated to the measured temperature using the Omega $\mathrm{HH} 11$ contact thermometer. 


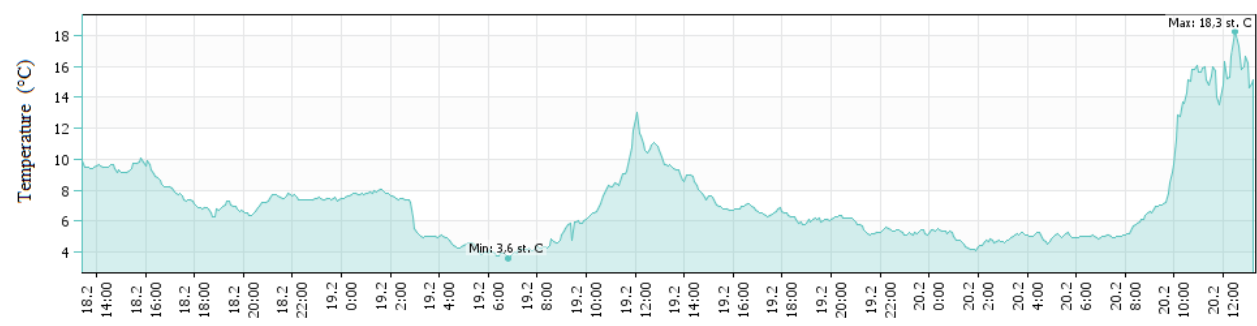

Fig. 4. External temperatures.

Table 1. Temperature and emissivity of the surfaces 1 through 7.

\begin{tabular}{|c|c|c|c|c|c|c|c|c|c|}
\hline & \multirow{2}{*}{$\begin{array}{c}\text { Surface } \\
\text { no. }\end{array}$} & \multicolumn{3}{|c|}{ Air temperature $\left({ }^{\circ} \mathrm{C}\right)$} & & \multirow{2}{*}{$\begin{array}{c}\text { Surface } \\
\text { no. }\end{array}$} & \multicolumn{3}{|c|}{ Air temperature $\left({ }^{\circ} \mathrm{C}\right)$} \\
\hline & & 5 & 7 & 9 & & & 5 & 7 & 9 \\
\hline \multirow{7}{*}{$\begin{array}{c}\text { Surface } \\
\text { temperature } \\
\left({ }^{\circ} \mathrm{C}\right)\end{array}$} & 1 & 11.7 & 14 & 17 & \multirow{7}{*}{$\begin{array}{c}\text { Emissivity } \\
\text { (1) }\end{array}$} & 1 & 0.86 & 0.86 & 0.86 \\
\hline & 2 & 15.2 & 15 & 16 & & 2 & 0.93 & 0.93 & 0.93 \\
\hline & 3 & 11.4 & 13.2 & 15 & & 3 & 0.84 & 0.84 & 0.84 \\
\hline & 4 & 16.9 & 18 & 22 & & 4 & 0.89 & 0.89 & 0.89 \\
\hline & 5 & 11 & 12 & 14 & & 5 & 0.91 & 0.91 & 0.91 \\
\hline & 6 & 10.5 & 11 & 14 & & 6 & 0.92 & 0.92 & 0.92 \\
\hline & 7 & 9.5 & 10 & 11 & & 7 & 0.94 & 0.94 & 0.94 \\
\hline
\end{tabular}

\subsection{Calculation of heat losses}

The pipes within the analysed conduit bridge were not of identical diameters, they also differed in surface temperature and surface emissivity. The process of identification of the heat loss of the piping system required for each pipe to be analysed separately. The following example illustrates the heat loss calculation for the pipe containing the medium-pressure steam at the air temperature of $5{ }^{\circ} \mathrm{C}$.

Nusselt number $(N u=147)$ and the coefficient of heat transfer by convection $\left(\alpha_{\mathrm{k}}=3.34 \mathrm{~W} \cdot \mathrm{m}^{-2} \cdot \mathrm{K}^{-1}\right)$ were determined according to the relationships given in section 2 .

Using CAD, a geometric model of the piping system was created. This model was used to read angles and distances to evaluate view factors between surfaces. The view factors were calculated using the Hottel's method. E.g. the view factor between tube No. 4 and the surrounding environment was 0.44 ; the heat loss by radiation to the environment amounted to $53.2 \mathrm{~W} \cdot \mathrm{m}^{-1}$.

The same method was applied to identify the view factors and then the linear radiation heat fluxes between individual pipes - see Table 2 .

Table 2. Linear radiation heat fluxes between individual pipes $\left(\mathrm{W} \cdot \mathrm{m}^{-1}\right)$.

\begin{tabular}{|c|c|c|c|c|c|c|}
\hline Pipe & 1 & 2 & 3 & 4 & 5 & 6 \\
\hline 1 & & -9.3 & 0.1 & -7.7 & 0.8 & 0.8 \\
\hline 2 & 9.8 & & 10.1 & -1.7 & 4.9 & 4.5 \\
\hline 3 & -0.1 & -10.1 & & -3.9 & 0.3 & 1.3 \\
\hline 4 & 7.7 & 1.7 & 3.9 & & 8.8 & 0 \\
\hline 5 & -0.8 & -4.9 & -0.3 & -8.8 & & 0.3 \\
\hline 6 & -0.8 & -4.5 & -1.3 & 0 & -0.3 & \\
\hline
\end{tabular}


A summary of the linear heat fluxes exchanged between all pipes by radiation is shown in Figure 5. Two pipes with the hottest surfaces (2 and 4) radiated the heat towards other pipes and the radiation losses of the remaining pipes were negative.

The resulting losses of individual pipes are shown in Figure 6. The pipe containing the medium-pressure steam (4), with the highest surface temperature, exhibited lower total heat loss than the pipes in the upper row of the system (1,2 and 3). This was caused by the smaller diameter of the pipe as well as the fact that it was partially shaded by the upper row of the pipes. The shading effect was most evident in the heat loss of the pipe containing the secondary hot water (5). The total linear heat loss of the system was $962 \mathrm{~W} \cdot \mathrm{m}^{-1}$.

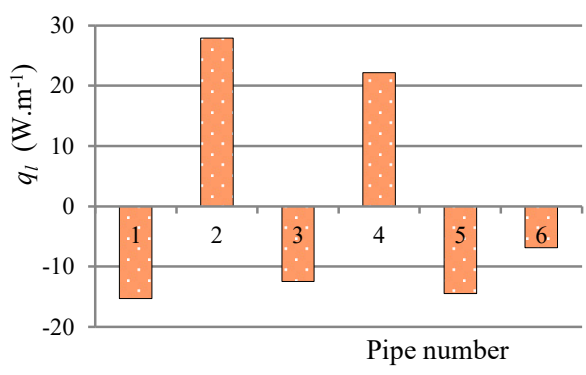

Fig. 5. Mutually exchanged linear heat fluxes by radiation.

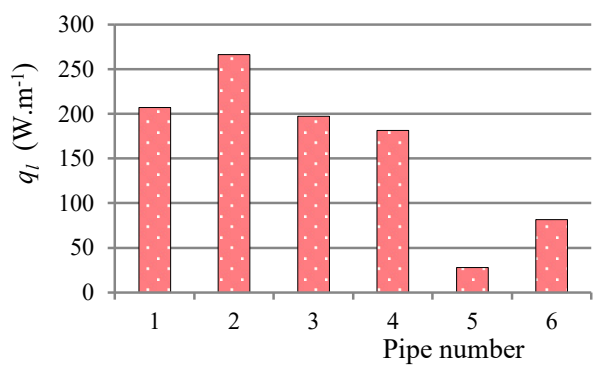

Fig. 6. Resulting linear heat loss of the insulated piping.

The inspection of the surfaces of individual pipes using a thermal imager revealed the places with the damaged or otherwise disturbed insulation - see Figure 7.

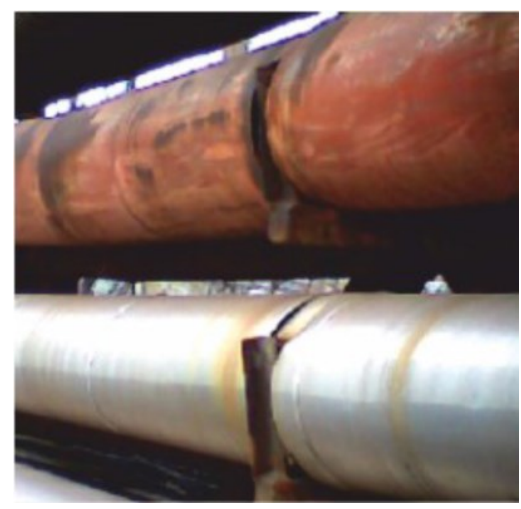

a)

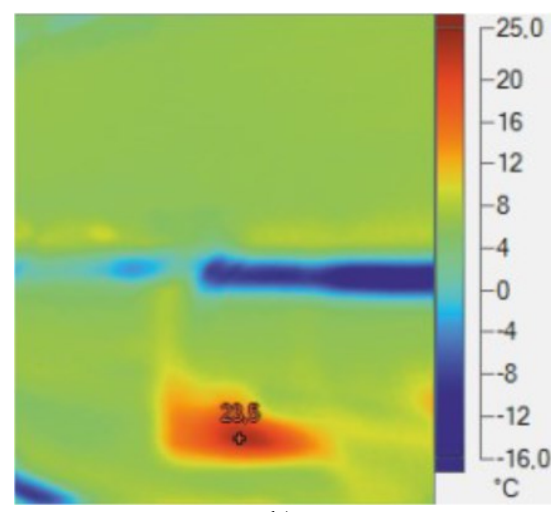

b)

Fig. 7. Thermal bridge - a) real image, b) thermal image.

Therefore, the method described above was applied to calculate the hypothetical heat loss of the piping system for the situation where all the pipes are without insulation (Figure 8). In addition to the location and diameter of the respective pipe, the temperature of the transported medium would also have a strong effect on heat loss. The total heat loss of such an uninsulated piping system would be $32.5 \mathrm{~kW} \cdot \mathrm{m}^{-1}$. 


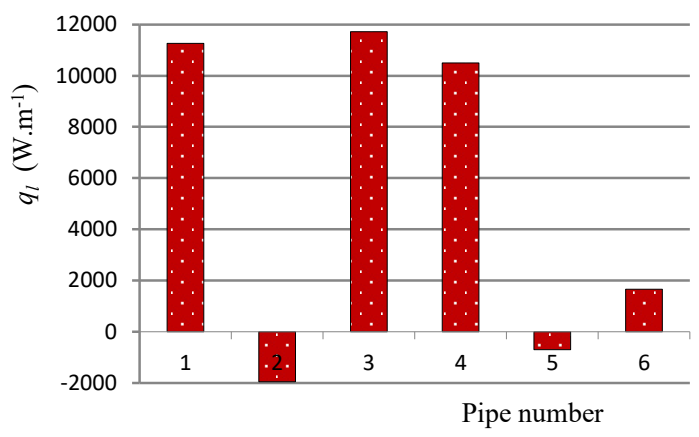

Fig. 8. Resulting heat loss of the uninsulated piping.

\section{Conclusion}

The performed measurements and subsequent calculations indicate that in a situation where the pipeline is shielded by another piping or any other structural barrier, the heat loss of such pipeline is lower. This was primarily seen in the case of the pipe containing secondary hot water (5) which showed significantly lower heat loss than the pipe no. 6, although the temperature of its insulation surface was higher.

A comparison of total heat losses shows that an uninsulated piping system would exhibit nearly 34 times higher heat losses than an insulated system. The good condition of the thermal insulation of the outdoor piping contributes significantly to the amount of energy consumed by the manufacturing operations in this particular enterprise.

The paper has been created within the project SP 2020/34-FMT VŠB TUO and project VEGA No. $1 / 0108 / 19$.

\section{References}

1. M. Rédr, M. Př́hoda, Základy tepelné techniky. Praha: SNTL (1991)

2. VDI-Wärmeatlas, 11. Aufl. Berlin: Springer Vieweg (2013)

3. T. M. Tritt, Thermal conductivity: Theory, Properties, and Applications. New York: Kluwer Academic/Plenum Publishers (2004)

4. M. Čarnogurská, M. Příhoda, M. Puškár, M. Fabian, R. Dobáková, M. Kubík, Measurement 94, 806-811 (2016)

5. M. Čarnogurská, R. Dobáková, Transfer inovácií, 31, 27-30 (2015)

6. J. Kalčík, K. Sýkora, Technická termomechanika, Academia Praha (1973)

7. J. R. Howell, A catalog of Radiation Heat Transfer Configuration Factors. [online]. [cit. 9. 1. 2020]. Available from: https://web.engr.uky.edu/rtl/Catalog/

8. K. Han, Y. T. Feng, D. R. J. Owen, CMES-COMP MODEL ENG 49, 143-161 (2009) 